\title{
Estudio de los elementos decorativos de la Puerta del Vino de la Alhambra de Granada
}

\author{
Ibrahim SALAMEH I
}

\section{INTRODUCCION}

En primer lugar se plantea el problema de la cronología de esta puerta. Tras su análisis es posible aventurar que fuese construida en dos fases. Así, la fachada exterior parece haber sido edificada en época de Muhammad III, mientras que la interior fue acabada por Muhammad V.

No se trata de una puerta de gran tamaño, monumental, aunque está ricamente decorada en azulejo con motivos geométricos y vegetales con un gran valor simbólico que tiene paralelos en la decoración oriental. En cuanto a su estructura, posee precedentes en puertas almohades en Marruecos que señalaremos más adelante.

En torno a su denominación, existen muchas opiniones. Por ejemplo, Antonio Gallego y Burín concluye: «su nombre lo debe al hecho de depositarse en ella desde 1554 el vino que consumian los vecinos de la Alhambra, exento del pago de impuestos por ordenanza de 15/7, pero algunos opinan que nace de haberse interpretado el vocablo al-hamrā,(roja) por aljamr (vino) pues, en su origen esta puerta parece que se llamó Bib-Alhamra (según cita de Aben-Aljațīb, en la biografía de Abū Sa"id el bermejo y de la crónica de Alfonso $X I$, al relatar el asesinato de Abū.l-walìd Ismāinl, nombre que confirma el supuesto de ser éste el acceso directo y exclusivo a la Alhambra Alta» (GALLEGO, 1963, p. 57 ).
Luis Seco de Lucena en su plano de la Granada islámica la denomina Puerta de la Alhambra (SECO DE LUCENA, 1910). Por su parte. Gómez Moreno dice: «...es una puerta de la que no se conoce otro nombre sino el moderno de Puerta del Vinos) (GÓMEZ MORENO MARTínEZ, 1965: p. 36), mientras su padre escribe: «cuyo nombre le proviene de venderse en ella vino durante el siglo XVI) (GÓMEZ MORENO GONZÁLEZ, 1884: p. 34), coincidiendo con Gallego y Burín (GALLEGO, 1963). Por nuestra parte, tras un análisis textual que seguidamente detallamos, nos inclinamos a pensar que esta puerta se llamaba Bāb al-Jamr, aunque después de la conquista cristiana desapareció su nombre islámico en favor de su traducción castellana, por lo que se conoce como Puerta del Vino. Hay dos textos, uno del Corán y otro que es un Hadīz del Profeta, que aclaran este extremo. Así, en el primero leemos: «Ésta es la semblanza del jardín prometido a los temerosos: Ríos de agua de inalterable olor, ríos de leche siempre del mismo sabor, ríos de vino, dulzor para los que beban, y ríos de miel purà). (Sūra de Muhammad, I5).

El hadīz dice: «La noche del viaje de Muhammad al cielo visitó todos los paraísos, vio los cuatro ríos, y preguntó a Gabriel sobre estos ríos.... Y he aquí que yo estaba junto a un árbol, vi una cúpula de perla blanca con dos puertas de esmeraldas y un candado de oro rojizo....observé que estos cuatro ríos salen debajo de esta cúpula.... cuando me aproximé al candado y dije en el

I Universidad de Granada. 
nombre de Dios, Clemente y Misericordioso, se abrió y entré en la cúpula... Cuando entré vi escrito sobre los cuatro ángulos de la cúpula:"en el nombre de la letra mim de bism, el de leche de ha de Alläh (Dios), el vino del mìm de al-Rahman y el de miel del mìm de al-Rahim"»» (ALAŠ'ART̄, 1987: p. 90)

Estos textos nos ofrecen unas claves fundamentales para comprender el verdadero origen del nombre:

I.- «Una cúpula de perla blanca con dos puertas de esmeraldas»). En la Puerta del Vino aparece representada la esmeralda por el color verde de las decoraciones vegetales y en las dos piezas cerámicas del mismo color localizadas en la parte superior del arco. Podemos considerar entonces que ésta es una de las dos puertas mencionadas en el texto, ya que el color verde es el dominante en la decoración. Por otro lado, está también presente el color blanco en la decoración inferior haciendo alusión a la cúpula.

2.- "Un candado de oro rojizo». El nombre de la puerta podría aludir al color rojo. Además la fachada exterior de la puerta contiene una llave. Creemos que esta llave representa un símbolo del modo de acceso al Paraíso, porque el creyente no puede entrar sin ella. Podría también ser una recomendación para que el creyente sea piadoso y aplique los cinco pilares del Islam, con objeto de entrar al final de su vida en el Paraíso a través de sus puertas.

Esto se observa de forma más clara todavía en la Puerta de la Justicia. En primer lugar vuelve a aparecer la misma llave (con el mismo significado simbólico) y, en segundo lugar, la acompaña una mano que con sus cinco dedos representa los cinco pilares del Islam (PAVÓN, 1967, p. 96). Los cinco dedos podrían significar asimismo las cinco oraciones diarias. Cuando Muhammad subió al cielo y se encontró a Dios; éste le ordenó que los creyentes rezaran cinco veces al día. La misma noche el profeta contempló las maravillas del Paraíso. Por eso se puede relacionar la simbología de la mano (el deber) con la llave que abre la Puerta del Paraíso (la recompensa) en la Puerta de la Justicia. En ella están representados todos los paraísos en la escala decorativa que la adorna. ${ }^{2}$

3.- «El vino del mimm de al-Rahman». La letra mìm aparece en las decoraciones vegetales del marco superior y que se denomina «marco mimi», muy común en el Egipto de la época mameluca y en Jerusalén, de donde procede este nombre (Figura I). Así pues, la letra MīM podría explicar la procedencia de la palabra «vino» en la denominación actual de la Puerta de al-Jamr.

Por el contrario, no creemos que esta puerta se denominase Puerta de la Alhambra Lo que cita Ibn al-Jațib sobre ella confirmaría esta hipótesis: «Dijo: Ha venido una mujer al sultán Muhammad b. Ismāill b. Faraŷ b. Nașr b. Ismāîl b. Nașr diciendo que le han robado en su casa. El sulțán le responde: "Si eso fue de noche, después de cerrar la Puerta de la Alhambra, entonces es una mentirosa") (IBN AL-JAṬ̄iB, 1977, l: p. 527).

Añade también: 'Alī b. 'Abd Allāh b. al-Hasan al Nibāhì al-Malaqĩ describió una palmera de la Puerta de la Alhambra, y dijo: "Vecina de la pared de la casa, de pie, para servir como un minarete... viviendo en la Alhambra Alta"») (IBN AL-JAṬīB, 1977, IV: p. 95).

Se puede deducir del primer texto de lbn al-Jațib que la puerta de la Alhambra se sitúa dentro de las murallas de la ciudad, por eso no parece que sea la puerta de acceso a la madīna, ya que la puerta de la Alhambra se abre y se cierra al pasar para entrar o salir de ésta. Tal condición no la cumple la Puerta de al-Jamr, porque está aislada de otros edificios y muy lejos de las murallas. Probablemente ésta era utilizada sólo para la salida y entrada del sultán a la zona civil y a la militar, ya que ésta es un límite común entre las dos áreas. Según el segundo texto de Ibn al-Jațíb se puede localizar la Puerta de la Alhambra en la Alhambra alta. 
Hay tres puertas: la de las Armas, la de la Justicia y la de al-Gudūr. No vamos a tratar de la de la Justicia, porque su nombre está confirmado por la inscripción que hay sobre la entrada. Así nos quedan sólo dos puertas y, probablemente, una de ellas ha de ser la llamada de la Alhambra.

\section{ESTUDIO DESCRIPTIVO DE LAS FACHADAS EXTERIOR E INTERIOR}

\section{Fachada exterior}

La puerta esta realizada con mampuestos de mediano y gran tamaño, separados por hiladas de ladrillo. Éste a su vez se encuentra cubriendo totalmente la esquina Norte de la puerta por ambas caras. La oriental es la única visible, ya que la meridional se halla adosada a una casa. El cuerpo superior de la fachada Oeste aparece también realizado en ladrillo y la cubierta de la puerta presenta un alero de madera y un tejado a tres aguas, cortado en su parte Sur. La zona central de la misma se encuentra construida en piedra arenisca de La Malaha, material éste preferido en las construcciones granadinas hasta el siglo XIV (PAVÓN, 1977: p. I I0), que se desarrolla en bancos de unos $15 \mathrm{~cm}$ de altura por término medio. Las jambas del vano de acceso están talladas en la misma piedra arenisca, formando sendas columnillas de piedra franca, muy estilizada, y rematadas con un capitel también de la misma piedra. El vano central presenta un arco de herradura apuntado y con dovelas alternantes, unas rehundidas y otras sobresalientes. Las albanegas que quedan a ambos lados del arco central se encuentran enmarcadas en la parte superior por un dintel que repite el esquema de las dovelas del vano principal, es decir, alternando las rehundidas y otras sobresalientes. En el centro actualmente tenemos una dovela de mármol con una llave tallada en bajo relieve. Por encima de este dintel hay un tablero de yeso con una inscripcion nasji cursiva adornada con motivos vegetales.

El tramo superior central de la puerta cuenta con una ventana geminada con dos arcos apuntados, separados por una columnilla muy estilizada. A ambos lados de la fachada encon- tramos restos de dos ventanas: la ventana de la zona Norte se halla parcialmente tapiada, dejando ver en un lateral su desarrollo, que cuenta con un arco polilobulado. Al Sur es visible la otra ventana, aunque esta segunda es de madera, y debajo de ella quedan huellas de haber existido un vano que fue posteriormente tapiado con ladrillo (Lámina I-figura 2).

\section{Fachada interior}

Su parte inferior está construida con piedra arenisca, como es normal en todas las puertas de la Alhambra. La utilización de piedra en la base obedece a que es necesario que ésta sea lo bastante fuerte como para soportar el peso de la construcción.

El arco de la puerta es de herradura, elaborado en ladrillo, y descansa sobre dos pilares de piedra arenisca. Está decorado con azulejo. En su parte superior existe una ventana con una columna en el centro sobre la que se apoyan dos pequeños arcos. Sobre ellas se puede apreciar el escudo de Muhammad V.

Rodeando la ventana existe una decoración de albanegas de yeso con inscripciones en árabe que describiremos posteriormente. Leopoldo Torres Balbás, durante enero y febrero de 1934, ordenó quitar el enfoscado de la parte alta de esta fachada (FERNÁNDEZ PUERTAS, 1980: pp. (20-121).

A ambos lados de la composición hasta ahora descrita existían unos paramentos estucados, dibujados y policromados, de los que se conserva un fragmento bastante grande en el lado superior derecho del arco (Lámina 2- figura 3).

\section{Historia de la fachada exterior}

Aún hay dudas sobre la fecha de construcción. Como primera referencia tenemos el tablero de yesería ocupado por tres líneas en letra cursiva, que cita un pasaje del Corán y que repite tres veces la salutación. He aquí el texto: «Me refugio en Dios huyendo de Satán el apedreado en el nombre de Dios y sobre su familia y compañeros y les conceda la salud. En verdad te hemos abierto una puerta manifiesta 
para que Dios te perdone tus pecados presentes y venideros, te colme de sus favores, te dirija por el camino recto y te ayude con su protección poderosa. Gloria a nuestro señor el sultán Abu Abdallah algani Billah. Gloria a nuestro señor el sultán Abu Abdallah algani Billah. Gloria a nuestro señor el sultán Abu Abdallah algani Billah»s (ALMAGRO, 1877: pp. 10-11)

Se refiere a Muhammad $V$, que reinó en Granada entre los años 1354-1391. No obstante, esta inscripción no ofrece referencias históricas respecto al edificio, de ahí la dilatada polémica que se mantiene sobre la antigüedad de esta puerta, de la que se pueden destacar tres opiniones interesantes. Gómez Moreno piensa que el edificio es anterior a Ismāīi I (GÓMEZ MORENO, 1965: pp. 36-38). Por su parte Basilio Pavón ha dicho que esta fachada fue construida por Muḥammad V y Yūsuf I (PAVÓN, 1977: p. I 14). Por último, Rafael Manzano cree que fue levantada en el reinado de Muhammad II (MANZANO, 1992: p. 40).

Para ofrecer una propuesta cronológica, hay que examinar diversos aspectos. Nos centraremos en primer lugar en cuestiones estilísticas.

Es evidente que las decoraciones vegetales de la fachada exterior resultan menos trabajadas que otras de la misma Alhambra. Es posible establecer una comparación entre distintas decoraciones vegetales de algunos sitios de la Alhambra. La decoración superior de la Puerta de la Justicia, tanto en la fachada interior como exterior, que se data en la época de Yūsuf I, puede compararse con la de la fachada interior de la Puerta del Vino, en la que hay azulejos, y la yesería que existe a ambos lados de la ventana gemela, así como con la otra decoración en yeso que se ve en la inscripción que aparece en la fachada exterior fechada en época de Muhammad $V$, pero también la decoración de las albanegas, que es de la época de Muhammad III.

Existen numerosas diferencias entre ellas, en particular en el elemento decorativo que se denomina pimiento, aunque es en realidad una hoja de palma de un sólo lóbulo. Las diferencias morfólogicas existentes en este elemento entre la Puerta de la Justicia y la Puerta del Vino llevan a pensar que son de distinta cronología (figura 4). Este elemento decorativo tiene precedentes almorávides, concretamente se ve en la mezquita de 'Abd al Wadìd de Argel (BOUROUIBA, 1981, p. 203) (figura 5) y en construcciones almohades de Marruecos, como la Bāb 'Agnaw y la Puerta de la Qașba de los 'Udāya (figura 6). Por su parte, Torres Balbás dijo: «Hay palmas lisas almohades con un solo lóbulo en forma de hoja alargada y el extremo curvo y puntiagudo, semejante a un pimiento, brotando con frecuencia del cáliz» (TORRES BALBÁS, 1955: pp. 26-27).

Creemos ver una continuidad de este motivo a lo largo de los distintos períodos de época musulmana. Un elemento a destacar es el hecho de que la inscripción que existe en la Puerta del Vino está elaborada en yeso mientras que en el resto de las puertas está hecha en piedra.

En la fachada exterior se ve el arranque de un arquillo lobulado en piedra monolítica. El modelo de la planta inferior se puede encontrar también en la puerta de acceso al Corral del Carbón, fechada por Gómez Moreno en el siglo XIV (GÓMEZ MORENO GONZÁLEZ, I892: pp. 196-199), así como en el del segundo patio del Generalife, si bien la planta de la Puerta del Vino gana en dimensiones y galanura (PAVÓN, 1977: p. I 14). Sin embargo el Generalife es de época de Muhammad III, pues hay una inscripción que menciona al sultán Ismā'îl I como restaurador de este palacio en 1312 (SÃLIM, 1986: pp. |50-15I). Su estilo es semejante al de la Bāb al-Ramla, mencionada por el escritor árabe al-'Umarī (AL'UMARĪ, 1927: p. 230). El hecho de que en el arco las dovelas del vano principal se alternen rehundidas y salientes (figura 7) nos recuerda a la Puerta del Vino. Pero también se observa en las dovelas del arco del mal llamado puente del Cadí, que fue construido en el siglo XI sobre el río Darro en Granada.

Otra influencia de época almohade la encontramos en su imposta, muy parecida a la de la fachada interior de la Bāb al-Rawah de Rabat y a la exterior de la Bāb de la Qașba de los 'Udāya también en Rabat, ambas del último cuarto de siglo XII . 
La puerta del Vino hay que ponerla en relación con el eje que marca la Calle Real, donde se localiza la mezquita mayor de la Alhambra, construida por Muḥammad III (IBN AL-JAṬīB, 1980: p. 63). La Calle Real traspasaba la Puerta del Vino en dirección a la Alcazaba. Sin embargo, la posterior construcción del aljibe, situado en la actual plaza de los Aljibes, rompió ese trazado, llegando la calle sólo hasta la misma Puerta.

Todo ello nos lleva a pensar que esta puerta fue construida al mismo tiempo que la mezquita, o sea en época de Muḥammad III, para ser usada por él cuando saliese de ella en dirección a la alcazaba, y viceversa. En realidad, la puerta marca la entrada del sulțán a dos ámbitos diferentes, uno el militar (la alcazaba) y otro el civil (la madina).

En el cuerpo superior hay una ventana con dos arcos gemelos y una columna central de aspecto arcaico (PAVÓN, 1977: p. 118). A ambos lados de la puerta hay otras dos ventanas. La primera, a la izquierda de la fachada, es lobula$\mathrm{da}$, casi cerrada. Podemos ver en ella una influencia de época almohade. Es el caso, por ejemplo, de las ventanas del alminar de la mezquita de Hasan, en Rabat. La segunda a la derecha está hecha en madera y construida posteriormente.

Por su parte, Rafael Manzano defiende que esta fachada es de época de Muḥammad II, aunque no da argumentos al respecto. Para aceptar esta opinión necesitaríamos conocer la fuente original de la que extrae esta conclusión. Sin embargo, el autor no facilita ninguna información al respecto (MANZANO, 1992: p. 40). La Arqueología ha de desempeñar un papel fundamental en la resolución de este punto. De momento, tan sólo se ha realizado una intervención en la Plaza de los Aljibes, aunque no aporta ninguna información sobre la puerta (BERMÚDEZ PAREJA, 1953: pp. 49-56).

Por último 'Abd Al 'Azīz Sālim data esta puerta en época de Muhammad II, relacionándola con un palacio de este sultán existente fuera de la Alcazaba (SÃLIM, 1986: pp. 142-144). Nuevamente nos falta la certeza y se evidencia la necesidad de un estudio arqueológico riguroso de la zona.
No obstante, y tras lo expuesto, creemos efectivamente que la fecha más cierta es la que establece la construcción de esta puerta en época de Muḥammad III.

\section{La decoración de la fachada interior de la Puerta del Vino}

La decoración empleada en la ornamentación de esta puerta es de un gran valor artístico. En ella se han utilizado los elementos vegetales y geométricos más representativos del arte nazarí en Granada. Está marcada esta decoración por la simetría y por el recargamiento decorativo, constante en todo el arte musulmán, que huye del espacio vacío. El azulejo vidriado es el que se utiliza como decoración. La técnica de vidriado surge en el mundo musulmán en el siglo VIII, disputándose la paternidad Egipto (Fusțāț), Persia y Mesopotamia (PAVÓN, 1991, p. 106). En el siglo IX hay azulejos en la decoración de la mezquita mayor de Qayrawān (862-863). Durante este período existían muy buenas relaciones entre la dinastía aglabī, en especial con el sulțán Abū Ibrāhīm Aglabī, de Marruecos, y el califa Hārūm Al-Rašĩd, de Bagdad (MARÇAIS, 1928: pp. 12-13). Desde Persia y Mesopotamia llegará el empleo de esta técnica decorativa a Ifríquīya, a la Qal'a de los Banū Hammad (siglo XI), desde donde pasará a alÁndalus a mediados del siglo XII (GONZÁLEZ, 1995: p. 114). Aquí se desarrollarán nuevas técnicas, coloridos y formas, llegando a su punto más álgido en la Alhambra de Granada durante la época nazarí.

En la Puerta del Vino de Alhambra la decoración en azulejo se localiza en dos partes. La primera es una banda que enmarca el arco. Los motivos decorativos utilizados son geométricos. Concretamente se trata de círculos entrelazados en cuyo interior se alternan otros motivos decorativos siguiendo un orden: almendra, escudo nazarí y estrella de ocho puntas (figura .8). Este esquema decorativo tiene una clara influencia de la época almohade en Marruecos, con paralelos en Bāb al-Rawāḥ de Rabat, Bāb 'Agnaw de Marrakech y la Puerta de la Alcazaba de los 'Udāya de Rabat (TORRES BALBÁS, 1955: láms. 32, 33 y 34). La técnica empleada para dibujar estos elementos es la cuerda seca. El 
motivo más destacable es el escudo, elaborado con cuerda seca, que emplea los colores verde, amarillo y blanco, separados por una línea de manganeso. La banda no contiene leyenda.

La segunda parte se encuentra en dos triángulos que enmarcan el arco en su parte superior. Ambos son simétricos y están rodeados por una inscripción en árabe que consiste en la repetición de una letra mim, cuya simbología ya ha sido explicada. Aquí se puede observar una clara influencia del arte oriental, presente en el caso de las construccciones del período mameluco en Egipto y Jerusalén, donde existen ejemplos parecidos a la Puerta del Vino, influencia tal vez propiciada por las buenas relaciones existentes entre Muhammad $\vee$ y el sultán al-Manșūr b. Ahmmad, de Egipto (FERNÁNDEZ PUERTAS, 1997: p. 23). De hecho, todos los edificios de El Cairo durante este periodo tienen este tipo de marco, como por ejemplo la madrasa al-Manșūr Qalawn, la madrasa al-Ašraf Qayt bay y la madrasa del sultán Hasan.

En el centro de ambos triángulos exiten dos círculos de doce lóbulos, en color verde delimitado por dos líneas de color dorado. En su interior se encuentra una estrella de doce puntas elaborada por el entrelazado de dos de seis puntas. Esta estrella puede simbolizar los doce meses del año mencionados en el Corán. Ambos son de color verde, una enmarcada por dos líneas de color negro y otra por dos líneas de color dorado. En el centro de la pieza y formando un ahuecamiento existe un fragmento de cerámica de color verde.

No sólo se ha empleado la técnica del azulejo, sino que también hay una decoración pintada, localizada en la parte superior de las paredes interiores de la puerta. Se trata de una serie de hexágonos trabados, pintados de color rojo sobre yeso, al igual que los que existían en el māristán de Granada, que levantó Muḥammad V (PAVÓN, 1977: p. 120). También podemos encontrar paralelos orientales de esta decoración aunque éstos están trabajados en piedra, como se ve en El Cairo, en un fragmento del púlpito de Qayt bay de Janqa Faraŷ b. Barqūq, y en Jerusalén en el sabīl de este mismo sul- tán. También aparece esta ornamentación en madera en la puerta de la madrasa al-Ašrafiya de Jerusalén, hoy en día en el museo al-Haram al-islamī (figura 9) (WALLS, 1993: p. 87).

Además existe decoración pintada en la parte superior de la fachada interior y a ambos lados de la ventana. Se trata de elementos imbricados, en color rojo, que se documentan en otras partes de la Alhambra, como la Sala de los Reyes y la Torre de Comares. Este esquema decorativo ha estado siempre presente en las artes antiguas y en especial en el arte musulmán oriental y occidental. La decoración imbricada aparece ya en el Mafŷar de Jericó, en Madīnat al-Zahrā', en el alminar de la Kutūbiya de Marrakech, en el alminar de la mezquita de Hasan en Rabat, etc.(figura I0) (PAVÓN, 1989: pp. 91-93).

Por último, existe otro elemento decorativo de gran importancia. Se trata de los mocárabes, vulgarmente llamados estalactitas. Son unas formas raras en tres dimensiones, creación propia del arte islámico. El nombre procede de la palabra árabe muqarnas. Con ella eran designadas en este idioma. Continúa llamándose así en Marruecos, donde todavía perdura su empleo (TORRES BALBÁS, 1955: p. 27). El material utilizado en su ejecución es muy variado. Principalmente se emplea el yeso, dada su facilidad de manejo, como se puede observar en multitud de sitios de la Alhambra, aunque también se encuentran hechos en madera, barro vidriado y piedra, como se puede observar en este último caso en la jamba de la fachada interior de la Puerta del Vino (Figura II). Sin embargo, no son abundantes los mocárabes trabajados en material pétreo, ya que la piedra no es muy empleada en la Alhambra, a excepción de las partes inferiores de las puertas, capiteles y jambas, donde sí aparece este tipo de decoración, como es el caso de esta puerta y de la de Siete Suelos.

La decoración de mocárabes aparece por primera vez en Oriente, en Persia, en la mezquita Gumbad 'Alī de Albarqū', fechada en 1056 (BOSCH, 1977: pp. 139-160), y en Irak, en el mausoleo del Imán al-Dawār al Norte de Samarra (TABBAA, 1985: p. 62). En el Norte de África 
todos los investigadores afirman que las decoraciones en mocárabes aparecen por vez primera en el siglo XI en Argelia, en la Qal'a Banū Hammad (GOLVIN, 1965: pp. 23-27). En al-Andalus los primeros mocárabes aparecieron en Almería (PAVÓN, 1991: p. 111.).

Aparte de la decoración geométrica y de los mocárabes, otro elemento muy importante empleado en esta puerta son los motivos vegetales. Éstos se localizan en la parte interior del marco. Los motivos más abundantes son los florales, en especial atauriques de palmera, una decoración muy común en la Alhambra.

La palmera es utilizada desde época muy temprana en la decoración islámica. Es uno de los motivos preislámicos más antiguos y con más larga perduración en el arte musulmán (TERRASSE, 1923: p. 150). La palmera es uno de los árboles del Paraíso. En el Corán, en la sūra al-Buqara n², aleya 266, se dice: «iAcaso no le gustaría a uno de vosotros tener un Jardín de palmeras y vides por el que corrieran ríos y en el que hubiera toda clase de frutos??».

El uso, por tanto, de este elemento decorativo es una clara alusión al Paraíso. Las referencias a la palmera siempre son idílicas: « ... los troncos de las palmeras del Paraíso son de oro rojo, sus muñones de berilo verde, sus racimos son de perlas blancas, sus ramas son túnicas, sus dátiles son como las cántaras de Hayar. Más blancos que la leche, más dulce que la miel y más suaves que la mantequilla y que (además) no tiene huesos, la longitud del racimo es de doce codos de arriba a abajo, al igual que las cántaras. Apenas (si) se arranca uno cuando Dios 10 repone (dejándolo) como estaba (antes)...») (HÃ̈BBB, 1997: p. 82).

La repetición sin fin de la hoja y tallos de palmera podría reproducir la sucesión sin límites de las palmeras del Paraíso.

En la parte interior del marco hay muchos elementos de este tipo. Es un entramado de líneas formadas por tallos y hojas, lo que le confiere gran complejidad. Existen hasta un total de nueve elementos decorativos diferentes elaborados a partir de las hojas de la pal- mera. Esta compleja decoración se inicia con la asociación de tres elementos que se localizan en la parte superior del triángulo y que no vuelven a repetirse. El arranque de la decoración es un elemento formado por dos hojas de palmera bícromas (verde y dorado) entrelazadas en su parte superior y unidas en la inferior por un lazo de tallos de color verde. En su espacio interior existe una hoja lanceolada de esta misma coloración. Este elemento se une a un segundo formado también por hojas de palmera en verde, negro y dorado, partida en dos, cuyas mitades forman dos volutas en cuyo centro existe una pequeña hoja dorada. A continuación enlaza con otro que representa una flor con tres pétalos verdes y un cáliz de color dorado. Éste sirve de unión con el círculo lobulado con el que contacta en tres puntos. Esta combinación se reproduce tanto hacia el lado inferior como superior del triángulo y desde aquí a lo largo de todo el espacio se desarrolla un complejo combinado de volutas construidas a partir de dos hojas de palmera diferenciadas entre sí sólo por la orientación que describe la curva de las hojas. Todas estas volutas están unidas entre sí por tallos, en color verde, que discurren bien por encima, bien por debajo de las hojas de palmera. En los tallos se pueden apreciar pequeñas hojas en las que se han empleado tres colores: verde, dorado y negro. La decoración se completa rellenando los huecos existentes, bien con pequeños puntos de color dorado o con tréboles cuyas hojas son de color negro enmarcadas en líneas y cáliz verde. El final de esta combinación, en los extremos del triángulo, son dos pequeñas flores, una en cada ángulo, formadas por dos hojas de color verde y cáliz dorado. Éstas se rematan con un pequeño punto que sería la continuación simbólica de la decoración, ya que ésta seguiría hasta el infinito (figura I2). La hoja de palmera también ha sido empleada como elemento decorativo en la fachada exterior. Sin embargo, entre ambas existen algunas diferencias, siendo la principal que el acabado de la decoración de la fachada interior es más cuidado y rico. Ambas decoraciones son diferentes a las también utilizadas en la Puerta de la Justicia. Nos apoyamos en eso para deducir que responden a diferentes momentos constructivos, en especial la fachada exterior de la 
puerta del Vino, que es la que presenta mayores diferencias. Por ello, creemos que pudo ser construida antes de Yūsuf I (figural3).

Creemos ver precedentes de esta decoración en época almohade en Marruecos, concretamente en Bāb al-Rawāḥ de Rabat, Bāb 'Agnaw, de Marrakech, y la Puerta de la Alcazaba de los 'Udāya, de Rabat (fig. I4) (TERRAS$\mathrm{SE}$, 1923).

Elaborada en yeso, en la parte superior de la fachada y a ambos lados de la ventana existe una decoración de albanegas con motivos vegetales y geométricos (estrellas de ocho puntas) muy complicada y rodeada por una inscripción en árabe que ha sido estudiada por Almágro Cárdenas (ALMAGRO, 1877: pp. 10-11), y que dice:

«El reino duradero y la gloria eterna.

La dicha, la fortuna y el cumplimiento de los deseos.

Que grande es el poder y la voluntad de Dios.

No hay fuerza sino Dios»»

Por último, vamos a describir el escudo de los nazaríes situado sobre la ventana y en su parte central. Está realizado en yeso y en su interior contiene una banda dragonada con la leyenda «Sólo Dios es vencedon», en árabe: Wa Iā gālib illā Allăh.

El escudo, de origen cristiano, se emplea por primera vez bajo Yūsuf I y está presente en innumerables sitios, como por ejemplo en la torre de Abū-I-Haŷy ây, construida bajo este emir. El esquema del escudo se mantiene en época cristiana, como ocurre en el Alcázar de Sevilla, aunque en su interior se alternan los leones y los castillos (FERNÁNDEZ PUERTAS, 1973: pp. 82-84). Las relaciones entre el reino nazarí y los reinos cristianos durante la segunda mitad del siglo XIV, y en especial entre Muhammad $V y$ Pedro I, permitió un intercambio de los estilos decorativos (SÃLIM, 1986: p. 5I).

Granada, como último reducto islámico de la Península, será el centro de acogida de los artesanos provenientes de los territorios conquistados, que tomarán contacto directo con el arte nazarí y lo difundirán por los reinos cristianos tras la conquista.

Si bien la forma del escudo es cristiana, su empleo simbólico como reflejo del poder ya tenía precedentes islámicos y, más concretamente, el uso de animales como símbolo de la fuerza. Por ejemplo, en Qașr de Jirbit al-Maf$\hat{y}$ ar, de Jericó, se emplean leones cazando gacelas. La pila de Bādīs, en realidad procedente de la Córdoba califal, tiene estas figuras. También es empleada esta simbología por el sultán alTāhir Bïbars, mameluco, que utiliza los leones en sus edificios como el puente $\hat{Y}$ isr $\hat{Y}$ indāz, al Norte de Palestina. En la Alhambra de Granada los leones son también expresión del poder en el llamado precisamente Patio de los Leones, obra de Muhammad $V$, englobándose este elemento dentro de los innumerables símbolos empleados en la arquitectura de palacio nazarī.

Finalmente vamos a hablar de la simbología de los colores utilizados en la decoración. La de la Puerta del Vino expresa, como ya hemos indicado, la simbología del Paraíso, pero no sólo con los elementos ya descritos, sino que ésta se ve reforzada con el empleo de algunos colores. Cada color tiene su significado simbólico en el Paraíso. Son cinco: blanco, verde, negro, azul y amarillo, separados en esta puerta por una línea negra para evitar su mezcla. Estos colores tienen su explicación en la descripción de las puertas y jardines del Paraíso contenidas en un hadit t tal como señala Puertas Vílchez: «La primera, Dār al-ŷalāl ( de la Gloria) está hecha de perlas blancas. La segunda, Dār al-Salam (de la Paz) es de amatistas violetas. La tercera, Yannat al-Māwà (jardín del refugio) es de esmeraldas verdes. La Cuarta, Y̧annat al-Juld (jardín de la eternidad) es de corales rojos y amarillos. La quinta, Ŷannat al-Na'imm (jardín de las delicias) es de plata blanca. La sexta, Ŷannat al-Firdaws (jardín del Paraíso) es de diamante rojo. La octava, Dār al-Qarār (casa de la eternidad), está hecha de ladrillos de oro rojo mezclados con ladrillo de plata". Podemos ver también que los colores expresan más de un significado. Por ejemplo, el verde y el amarillo simbolizan los vestidos que se usan en el Paraíso, tal como se recoge en el Corán: "Ellos tendrán los jardines 
de 'Adan por los cuales corren los ríos, en ellos se adornarán con pulseras de oro y llevarán vestidos verde de raso y brocado, recostados en divanes"(Sūra al-kahif ) (PUERTAS, 1990: p. 155).

\section{FUENTES}

Abū Hasan AL-AŠ'AR̄̄ (1987): Kitāb šaŷarat al- yaqin. Edic. y traduc. de Concepción CASTILLO CASTILLO. Madrid.

'Abd al-Malik Ibn HABĪB (1997): Kitāb wașf al-Firdaws. Edic. y traduc. de Juan Pedro SALA. Granada.

Ibn AL-JAṬīB (1977): Al-Ihāța fĩ ajbār Garnāța. Edic. M. A.'INÃNN. El Cairo.

Ibn Al JAṬ̄iB ( 1980): Al-Lamha al-badriyya fî-dawla al-nașriyya. Beirut.

Ibn Faḍ Allāh AI-'UMARĪ ( 1927): Masālik al-abșār fĩ mamālik el amșār. I. L'Afrique, moins I'Egipte. Traduc. GAUDEFROY-DEMOMBYNES. París.

\section{BIBLIOGRAFÍA}

ALMAGRO CÁRDENAS, Antonio ( 1877): Inscripciones árabes de Granada. Granada.

BERMÚDEZ, Jesús (1953): "Exploraciones arqueológicas en la Alhambra". Miscelánea de Estudios Árabes y Hebráicos. II, pp. 49-56.

BOSCH VILÁ, Jacinto (1977): "¿Mocárabes en el arte de la Taifa de Almería?". Cuadernos de Historia del Islám.VIII, pp. 139-160.

BOUROUIBA, Rachid (I98I): L'art religieux musulman en Algérie. Alger.

FERNÁNDEZ PUERTAS, Antonio (1973): "En torno a la cronología de la Torre de Abū I-Haŷȳāŷy", en Actas de XXIII Congreso Internacional de Historia del Arte. Vol II , pp. 82-84.

FERNÁNDEZ PUERTAS, Antonio (1997): "The three Great Sultan of al-Dawla al-Ismailiyya". Journal of the Royal Asiatic Society. 7, pp. I-26.
FERNÁNDEZ PUERTAS, Antonio (1980): La Fachada del Palacio de Comares. Granada.

GALLEGO Y BURÍN, Antonio (1963): La Alhambra. Granada.

GOLVIN, Lucien (1965): Recherches archéologiques à la Qala Banu Hammad. París.

GÓMEZ MORENO, Manuel (1884): Guia de Granada. Granada.

GÓMEZ MORENO MARTíNEZ, Manuel(1965): "Granada en el siglo XIII". Cuadernos de la Alhambra. II , pp. $2-41$.

GONZÁLEZ RAMÍREZ, Maria Isabel (1995): El trazo geométrico en la ornamentación del Alcázar de Sevilla. Sevilla.

MANZANO, Rafael (1992): La Alhambra. El universo mágico de la Granada Islámica. Madrid.

MARÇAIS, Geoges (1928): Les Faïences a reflets métalliques de la Grande mosquée de Karairouan. París.

PAVÓN MALDONADO, Basilio (1977): "Puertas y torres de la Alhambra". Cuadernos de la Alhambra. Anejo II, pp. 109-122.

PAVÓN MALDONADO, Basilio (1989): El arte hispanomusulmán en su decoración geométrica. Una teoría para un estilo. Madrid.

PAVON MALDONADO, Basilio (199|): El Cuarto Real de Santo Domingo. Granada.

PUERTAS VÍLCHEZ, Jose Miguel (1990): Los códigos de utopía de la Alhambra de Granada. Granada.

SÃLIM, Saīd 'Abd al-Azīz (1986): Al-Masāŷid wa-l-qușūr fī al-Andalus. Alejandría.

SECO DE LUCENA ESCALADA, Luis (1910): Guía de Granada. (Plano de Granada Arabe año 1910). Granada.

TABBAA, Yaser (1985): "The muqarnas dome: its origin and meaning". Muqarnas. An annual on Islamic Art and Architecture. 3, pp. 61-74.

TERRASSE, Henri (1923):" La décor des portes anciennes du Maroc". Hesperis. I, pp. 147-I74.

TORRES BALBÁS, Leopoldo (1955): "Arte almorávide y almohade", Ars Hispaniae. Vol. III. Madrid.

WALLS, Archie G. (1993): " Ottoman restoration to the sabil and the madrasa of Qaytbay in Jerusalem", Muqarnas. An annual on Islamic Art and Architecture. II pp. 85-97. 


\section{RESUMEN}

Este trabajo se centra en el estudio de los elementos decorativos existentes en la Puerta del Vino de la Alhambra de Granada, que, lógicamente, pueden ser interpretados a la luz de la religión islámica. Los elementos empleados en la decoración no son sólo bellos sino que contienen un significado más o menos velado. Por tanto, no se trata sólo de lo que se ve, sino que hay que analizar en profundidad las decoraciones, los colores, etc. En el caso de la Puerta de $\checkmark$ ino los elementos decorativos contienen símbolos que aluden al Paraíso, por ello planteamos la hipótesis de que esta puerta represente la Puerta del Paraíso

\section{PALABRAS CLAVE}

Arqueología Medieval. Alhambra. Puerta del Vino. Decoración. Azulejos.

\section{ABSTRACT}

This essay is focused on the study of the decoration of the Wine Gate (Puerta del Vino) of the Alhambra (Granada), which obviously can be interpreted by means of the Islamic religion.

The elements used in the decoration are not only beautiful but, hold a more or less shadow meaning as well.

Therefore, it is necessary to use a depth analysis of the decorative pattern, the colours and so on. Concerning the Wine Gate the decorative elements contain symbols refering to the Islamic paradise, that is the reason why we forward the hypothesis that this gate represents Paradise's Gate.

\section{KEY WORDS}

Medieval Archeology. Alhambra. Wine Gate. Decoration. Glazing potery 
Fig. I. El marco mimi

Fig. 2. Fachada exterior de

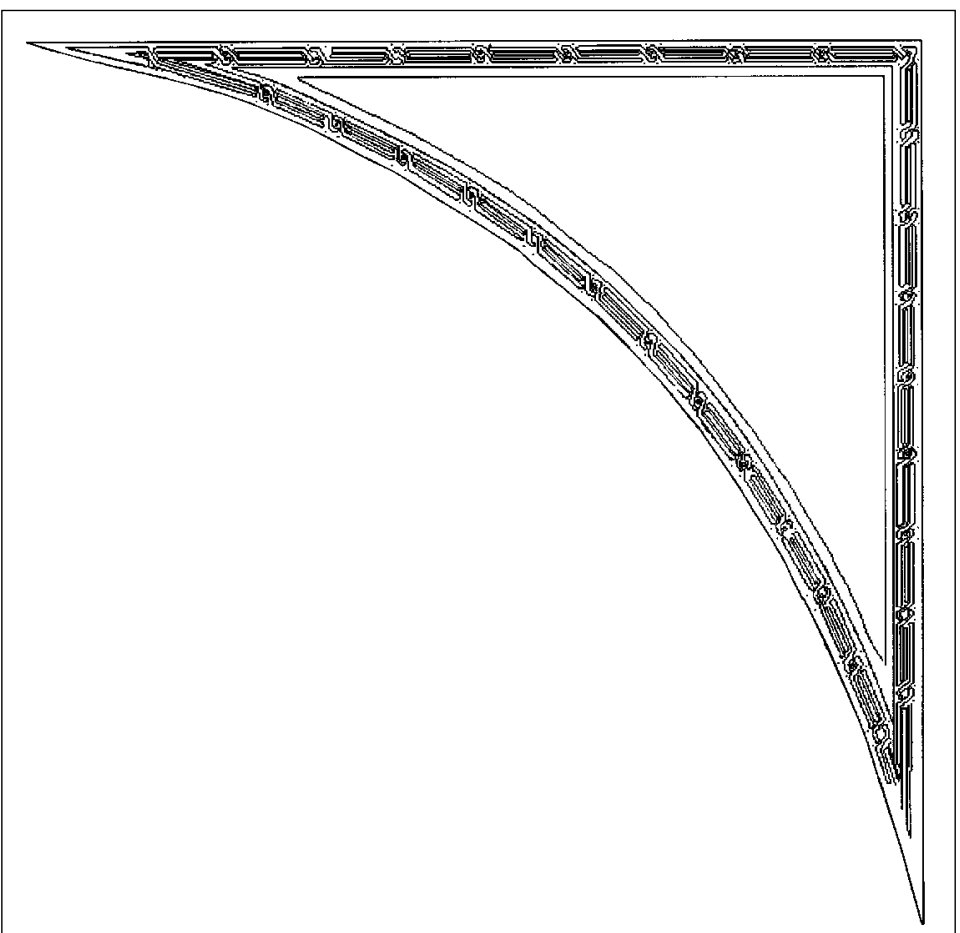

la Puerta del Vino. (Alhambra)

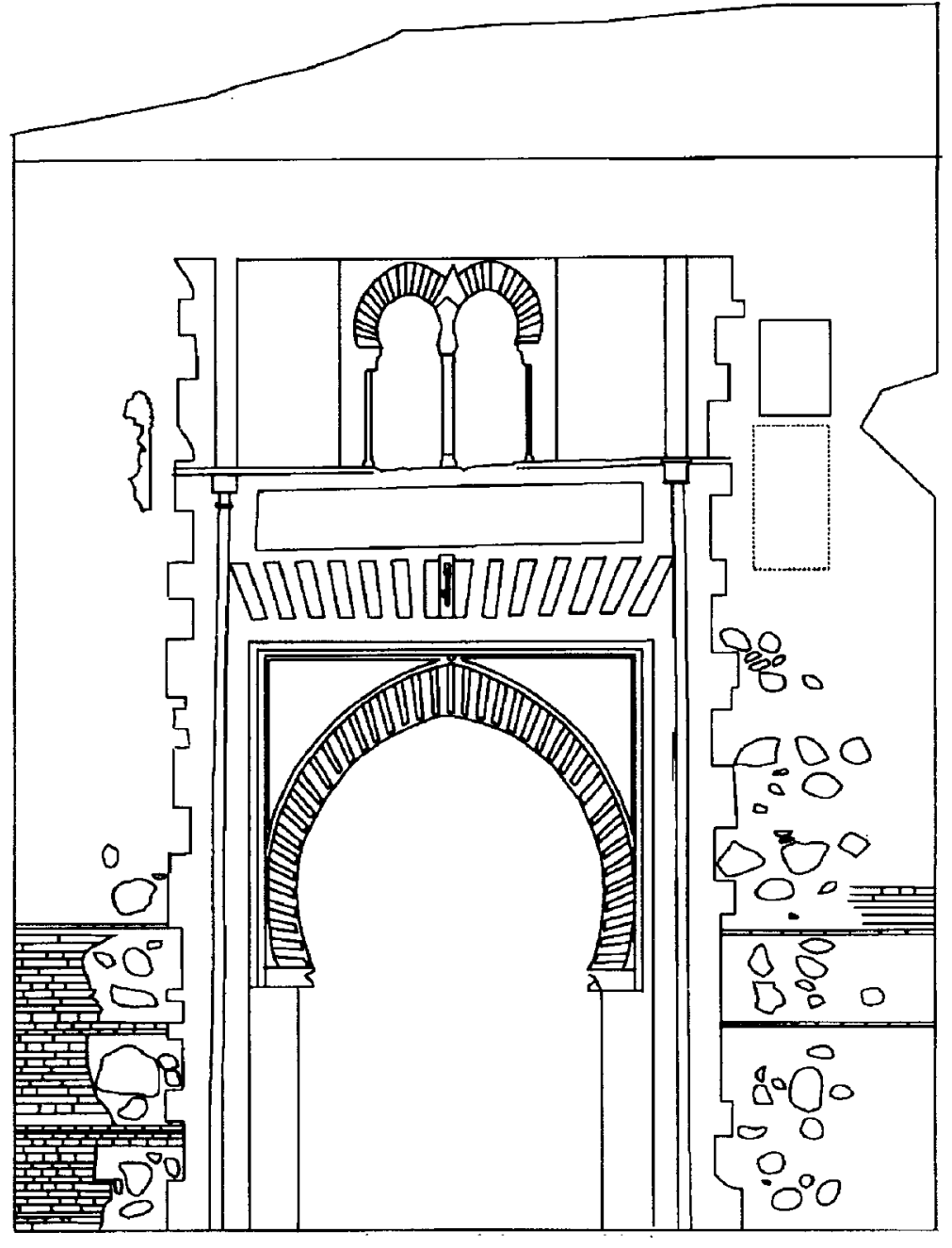




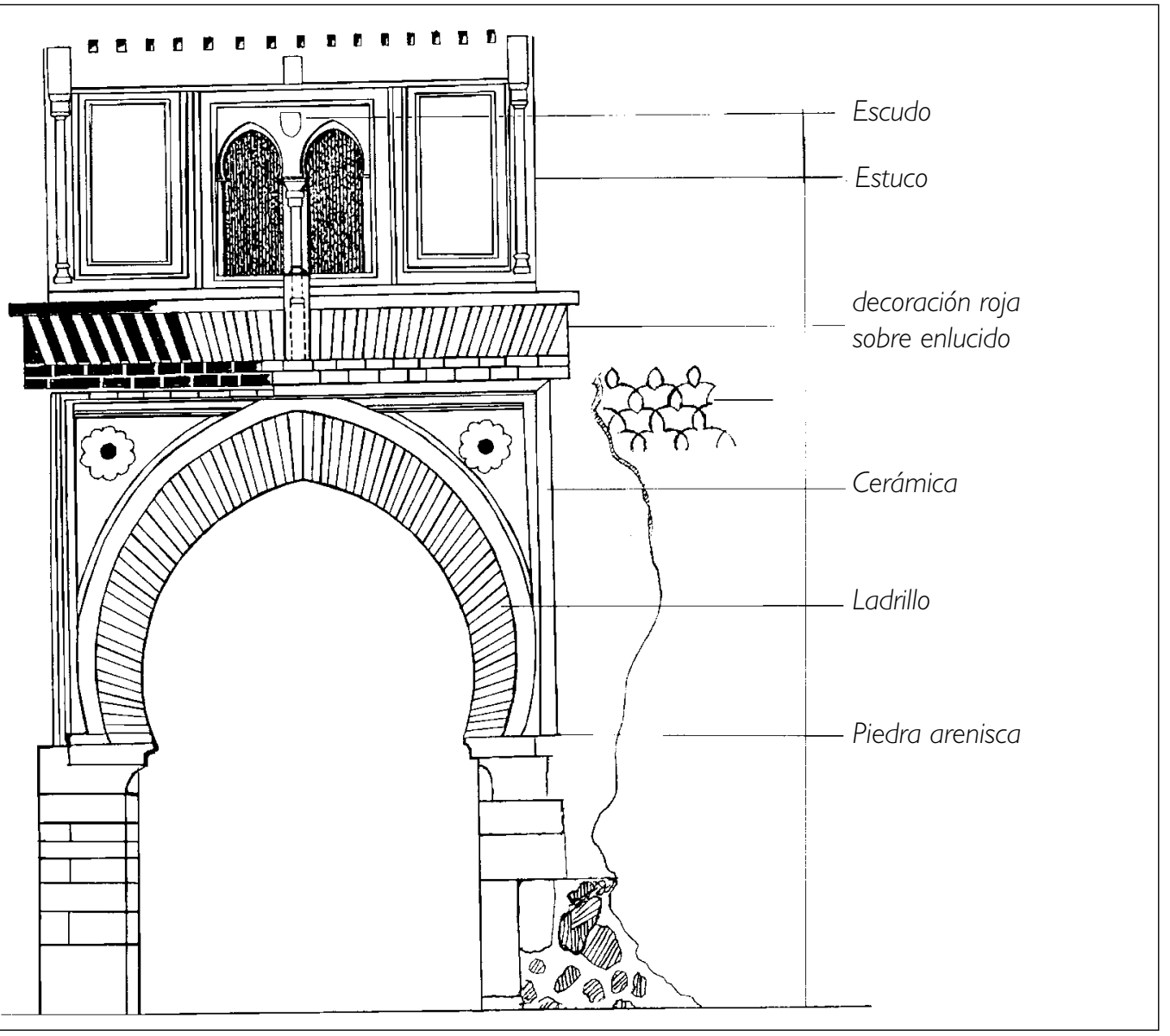

Fig. 3. Fachada interior de la Puerta del Vino. (Alhambra)

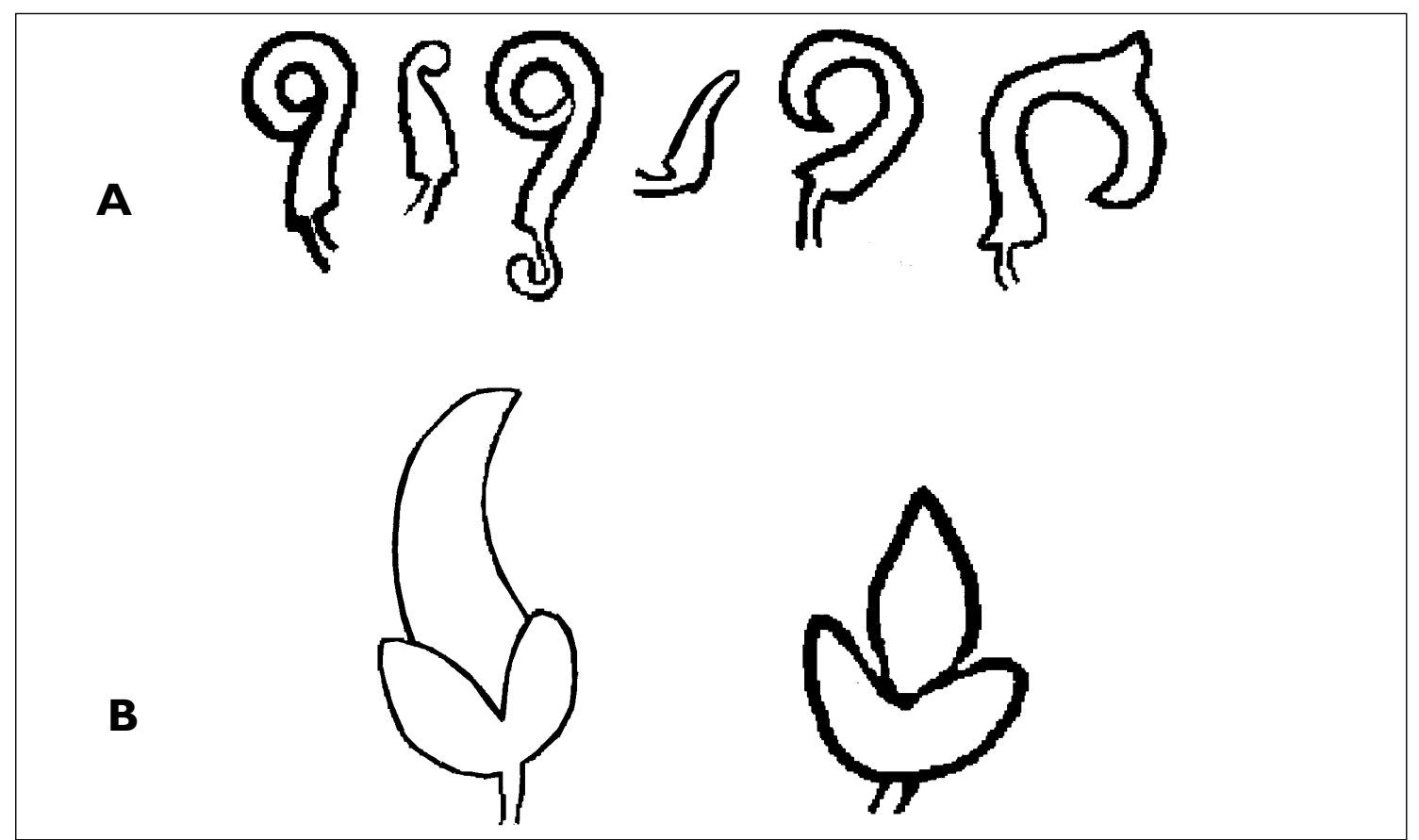

Fig. 4. A: Decoración de Palmera o pimiento en la fachada exterior. (Puerta del Vino) B: Decoración de Palmera en la fachada interior. (Puerta de la Justicia) 


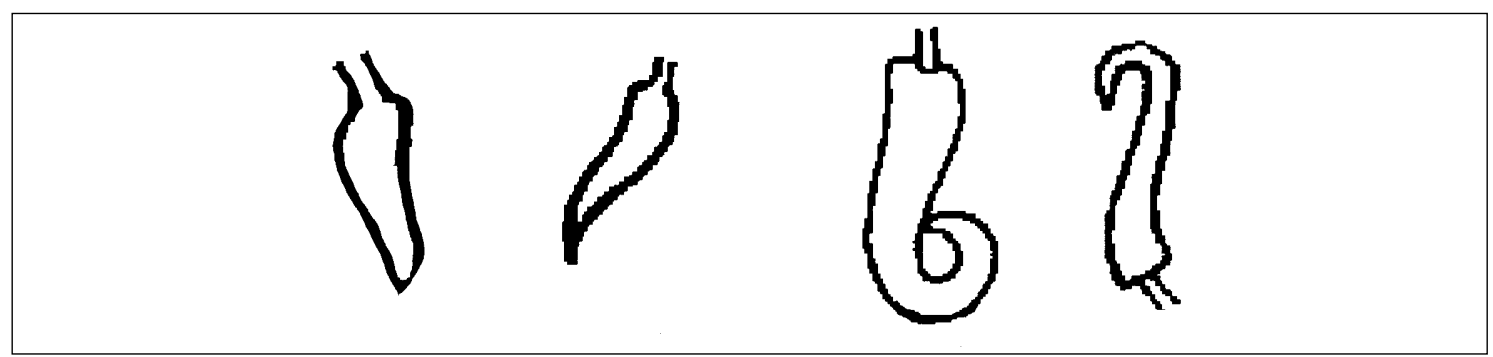

Fig. 5. Decoración de Palmera en la Mezquita de 'Abd al-Wadid de Argel

Fig. 6. A: Palma bāb 'Agnaw. B: Puerta de la 'Udāya de Marrakech
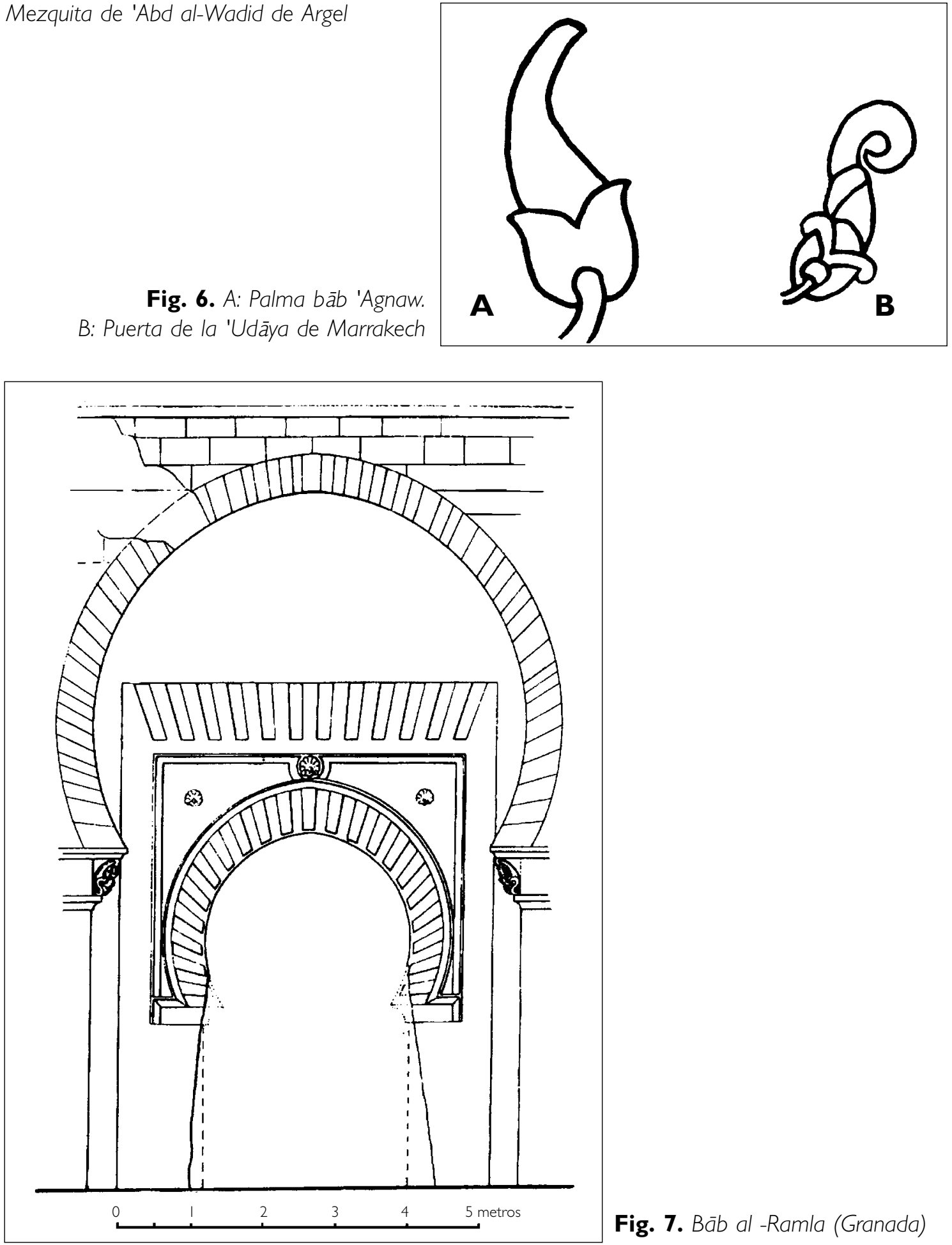

Fig. 7. Bāb al -Ramla (Granada) 
Fig. 8. Decoración en azulejo sobre el arco de la fachada E de la Puerta del Vino. (La Alhambra de Granada)

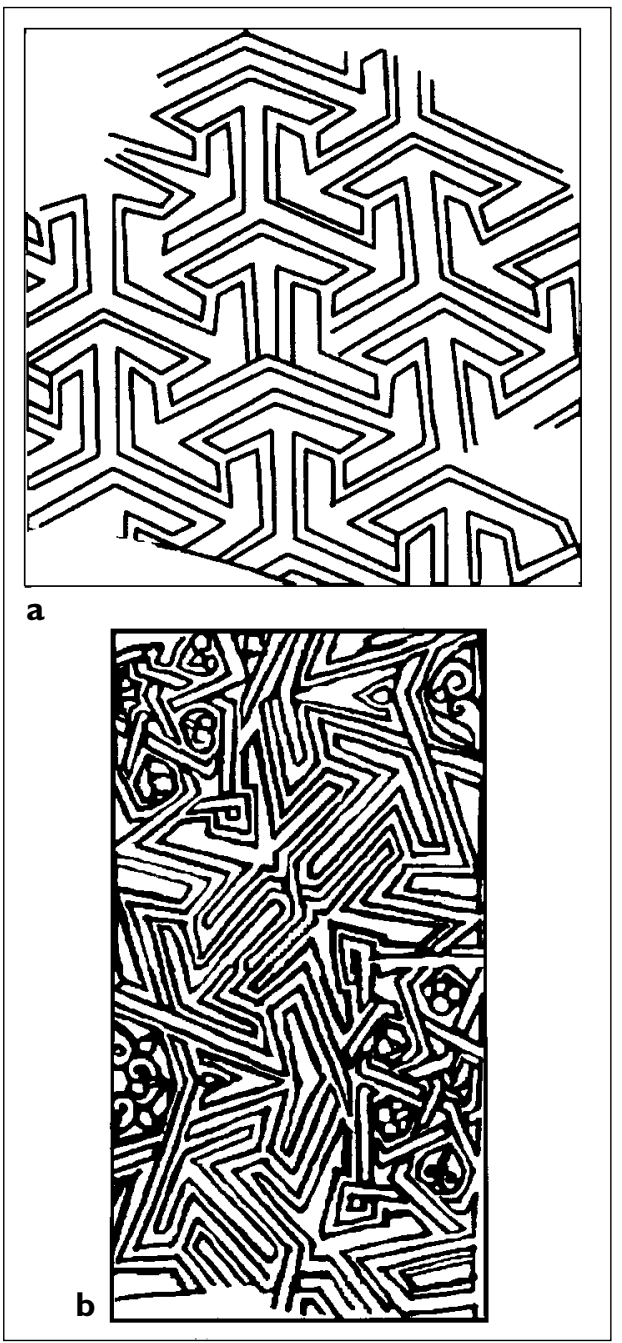

Fig. 9. a: Decoración geométrica de la Puerta del Vino. (La Alhambra de Granada) b: Decoración geométrica en el Sabil del Sulțān Qaitbay (Jerusalén)

Fig. 1 10. Decoración imbricada: a: Puerta del Vino.

b: Puerta del Vino (ventana).

c: Madinnat al-Zahrā (Córdoba).

d: Qașrn Jirbit al-Mafŷar (Jericó).

e: Mezquita de Hasan, alminar (Rabat)
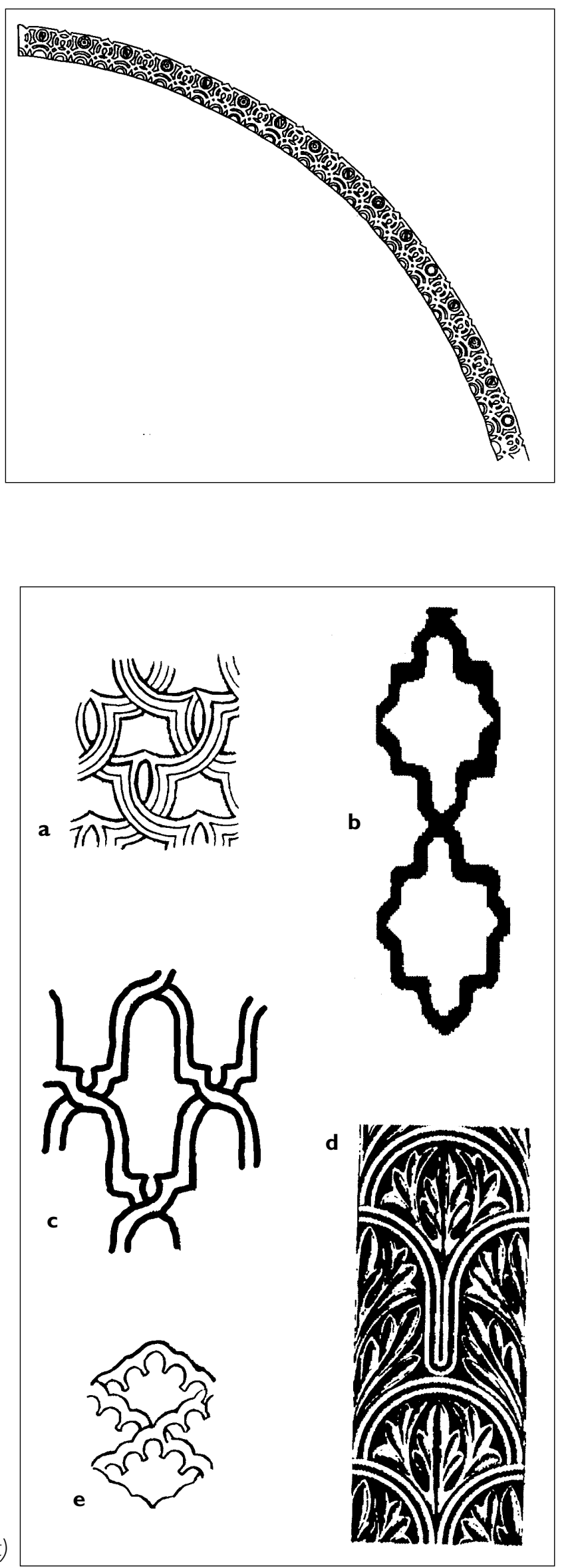


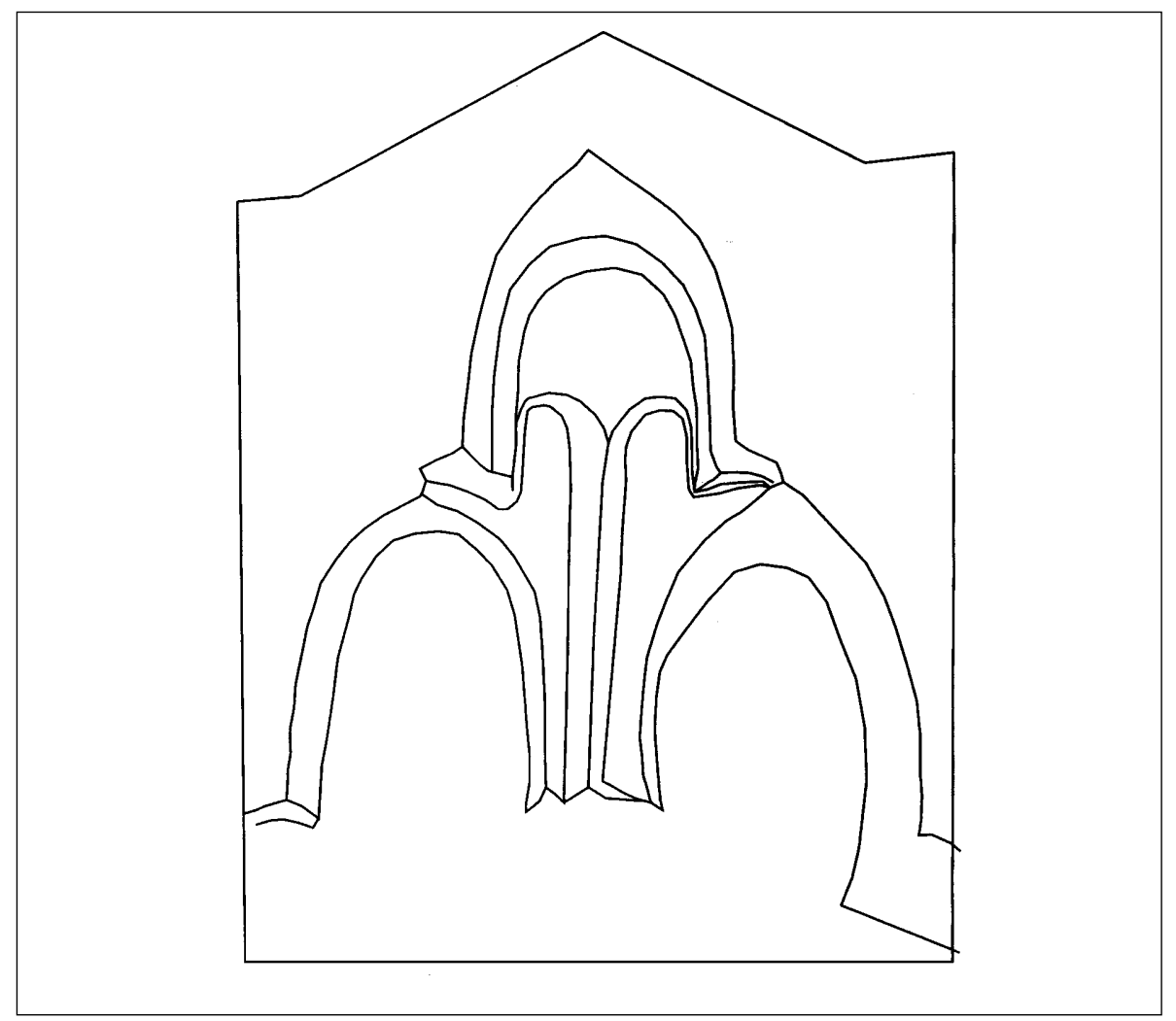

Fig. I I. Mocárabes de las jambas de la Puerta del Vino. (La Alhambra. Granada)

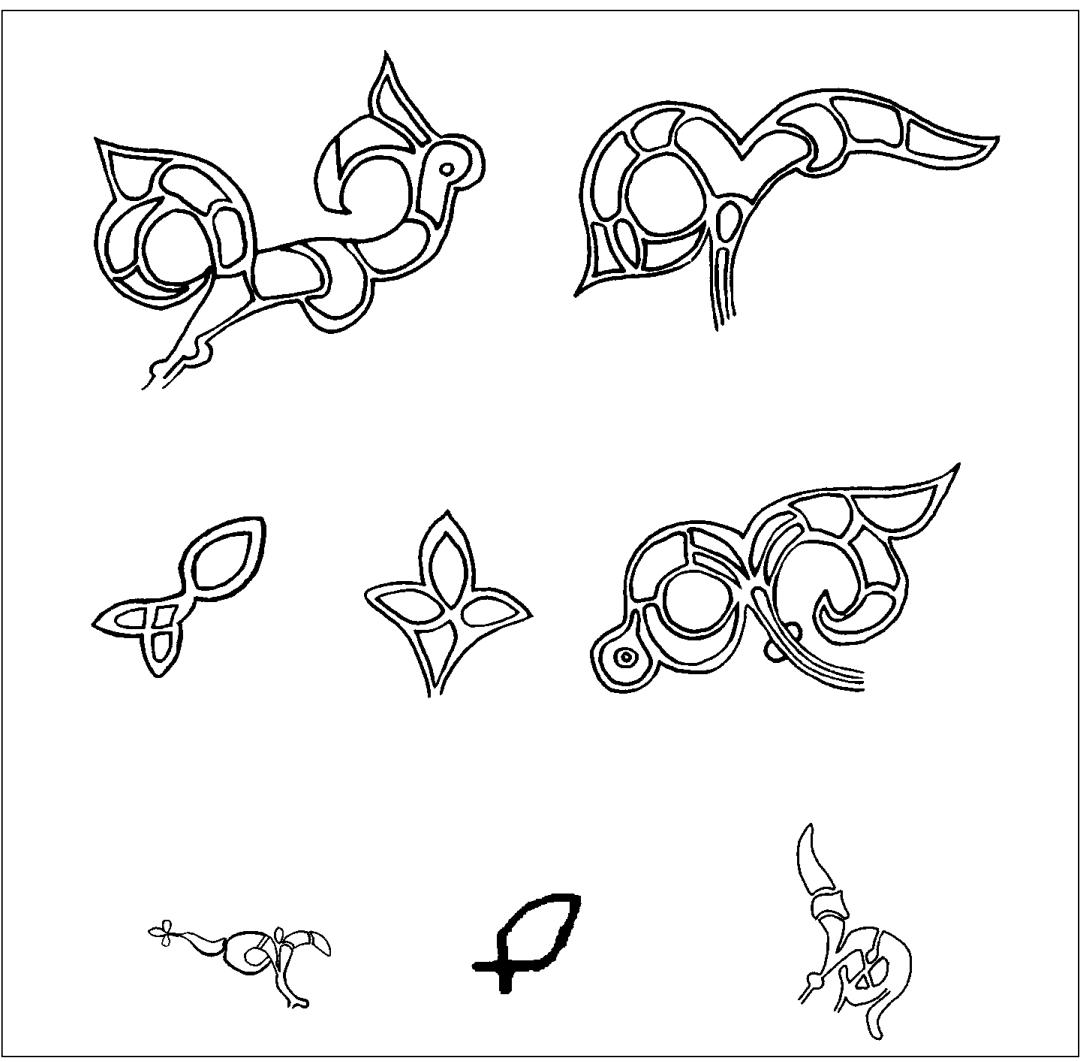

Fig. I2. Decoración de palmera de la fachada interior (Puerta del Vino) 


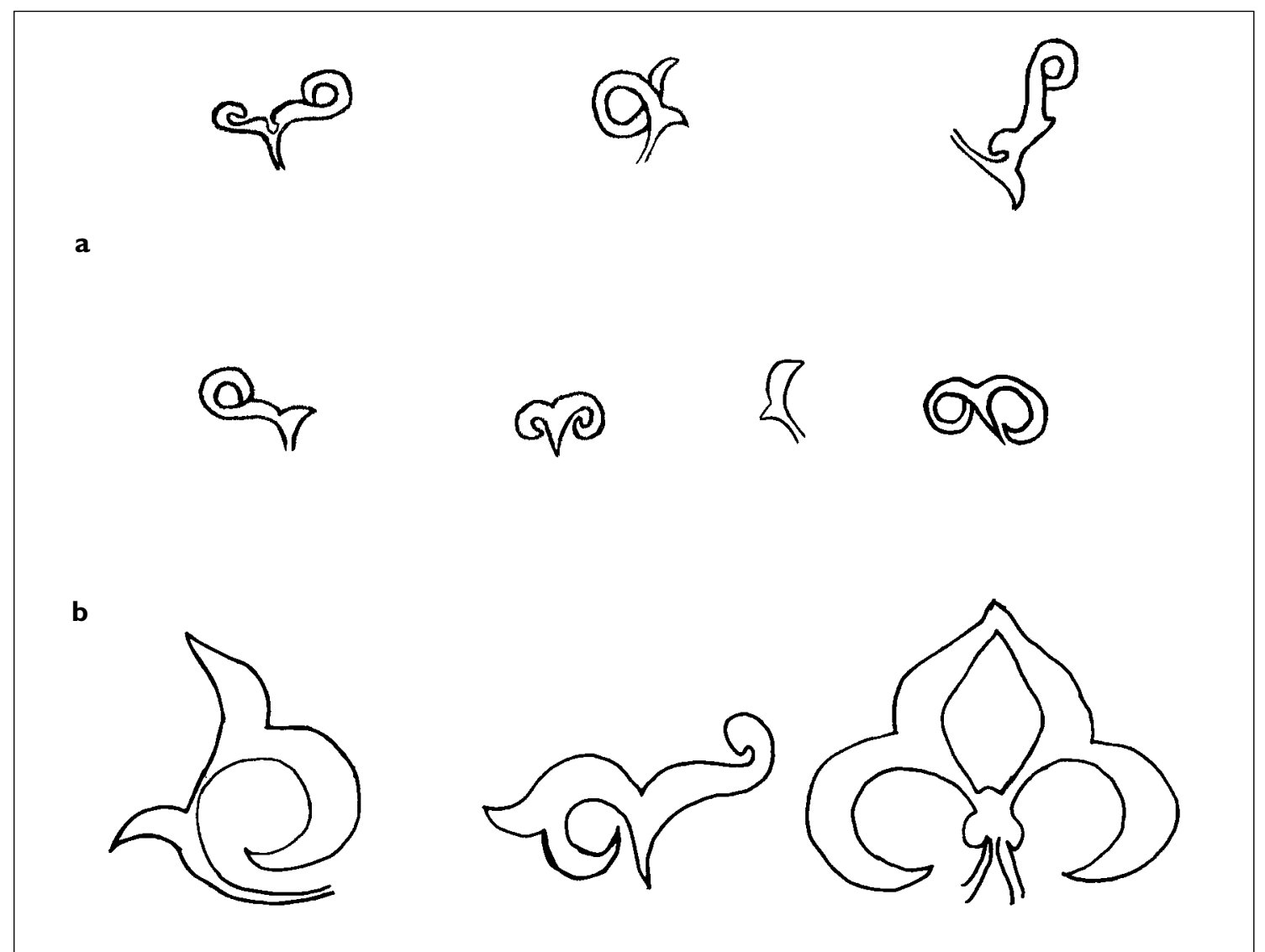

Fig. I3. a: Decoración de palmera en la fachada exterior. (Puerta del Vino).

b: Decoración de palmera en la fachada interior. (Puerta de la Justicia)

Fig. I4. Decoraciones en palmas en: a: Bāb 'Agnaw de Marrakech.

b: La Puerta de la Qasba de 'Udàya. c: Bāb er-Rouāh de Rabat

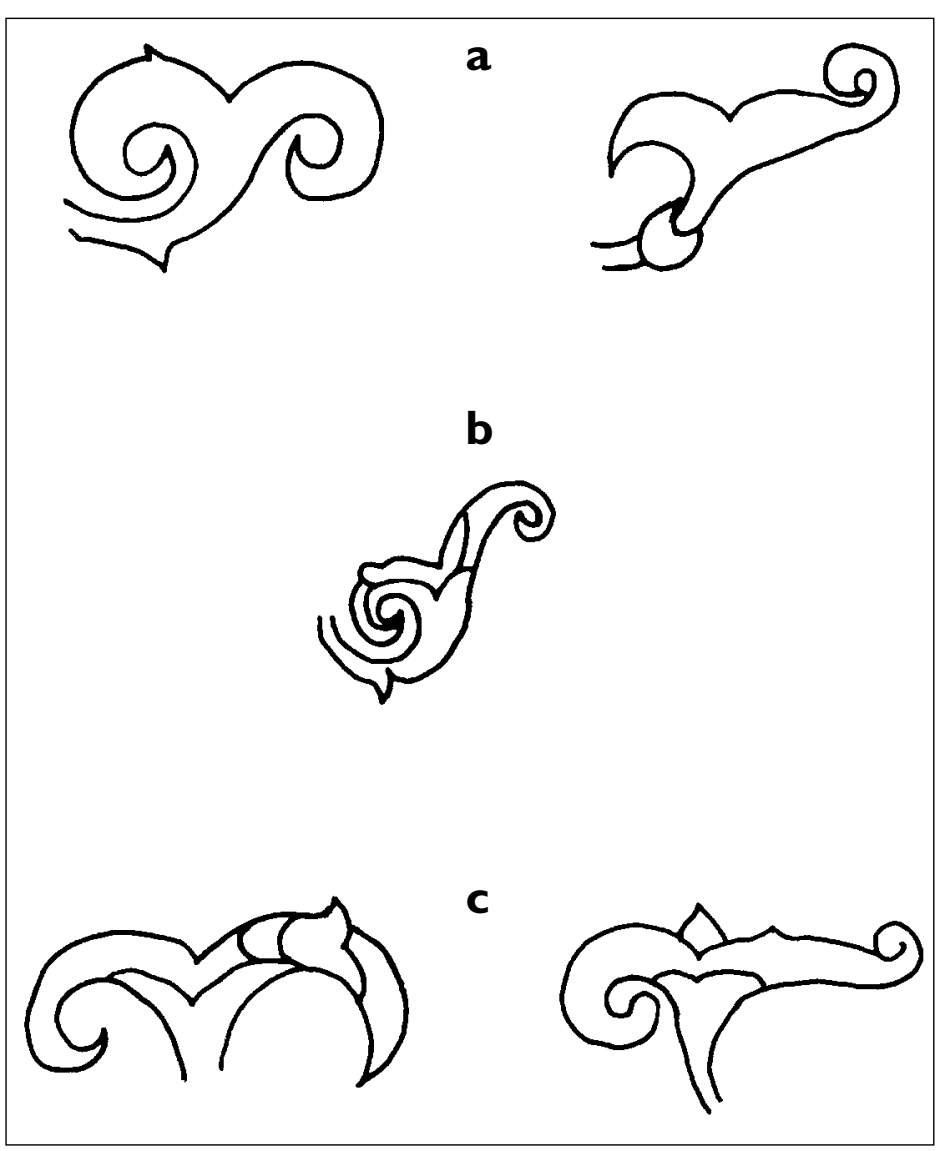




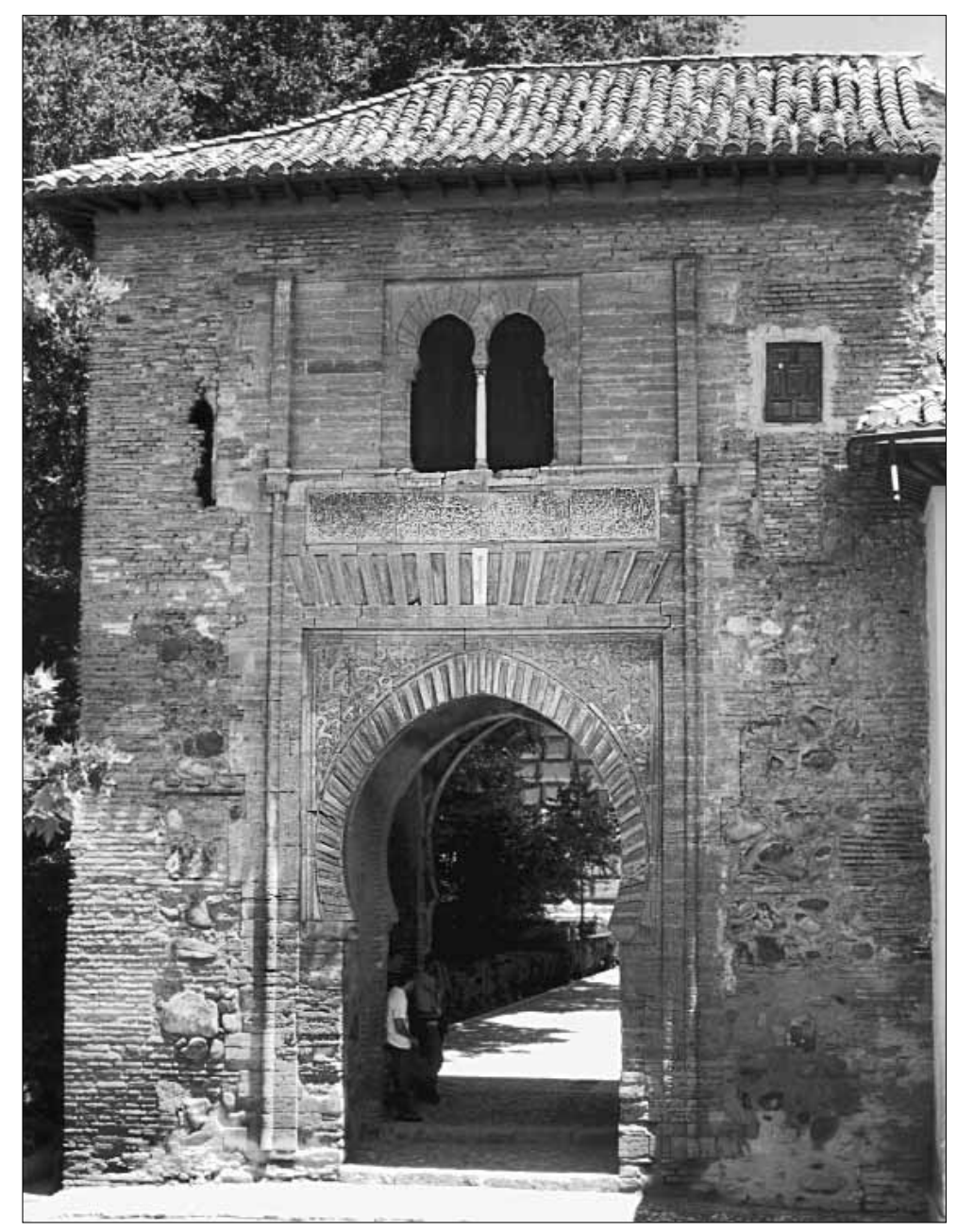

Lam. I. Fachada exterior de

la Puerta del Vino (Alhambra)

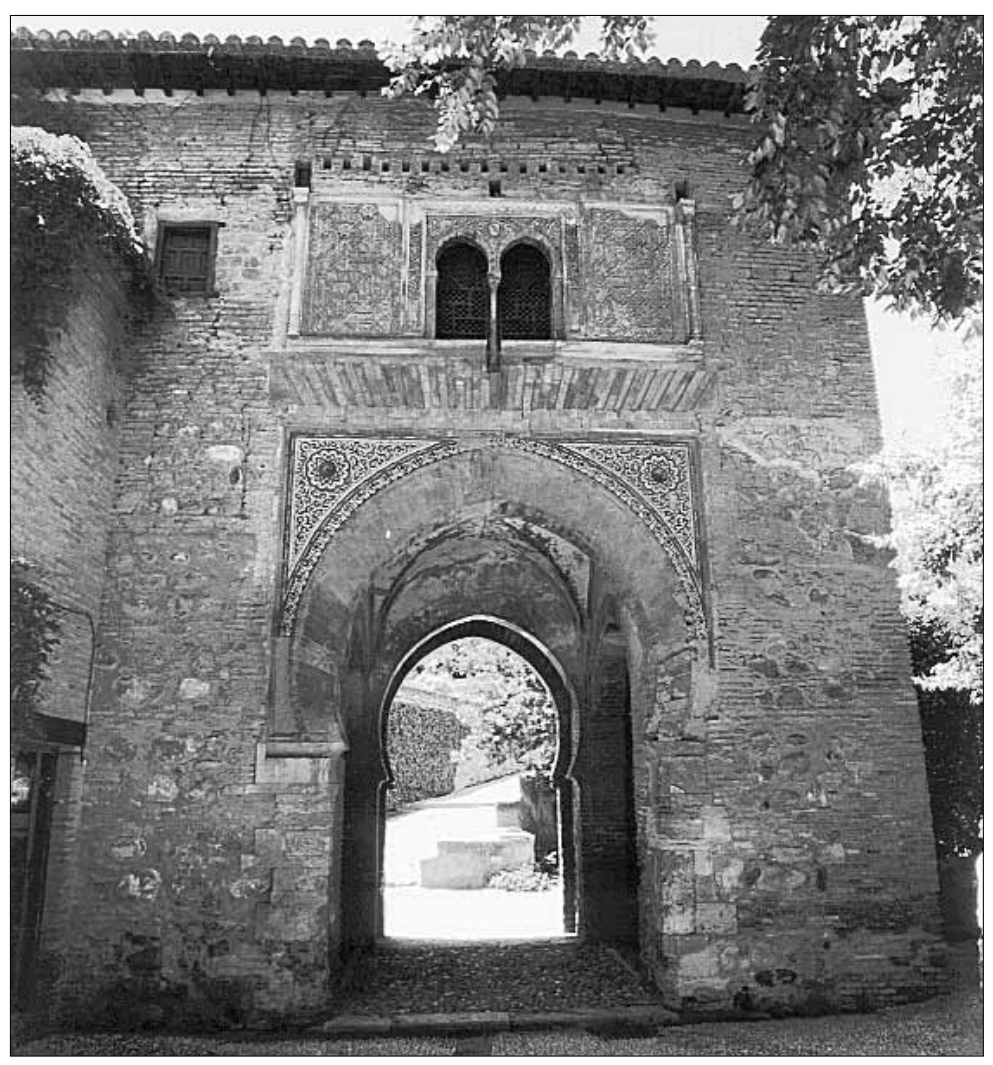

Lam. 2. Fachada interior de la Puerta del Vino /Alhambra) 